Bangladesh J. Bot. 48(4): 1193-1197, 2019 (December)

\title{
ANALYSIS ON THE ACCUMULATION OF ORIDONIN IN DIFFERENT PORTIONS OF ISODON RUBESCENS (HEMSLEY) H. HARA
}

\author{
Jian Zaiyou*, Xu Guifang and Dai Lei \\ Henan Institute of Science and Technology, Xinxiang, China, 453003 \\ Henan Collaborative Innovation Center in Modern Biological Breeding, 453003, China
}

Keywords: Isodon rubescens, Oridonin, Accumulation, RP-HPLC

\begin{abstract}
Analysis on the accumulation of oridonin in different parts of Isodon rubescens was studied. The contents of oridonin in all parts of I. rubescens were analyzed with RP-HPLC. The results showed that the differences between the contents of oridonin in the different parts of I. rubescens are extremely significant. The content of oridonin in the leaf of I. rubescens is higher than that of other parts. The content of oridonin in the stem was close to that of leaf. The root of I. rubescens had lowest content of oridonin in the three portions. But the content of oridonin in the root obtained was $0.0811 \mathrm{mg} / \mathrm{g}$. The root in long run should be utilized to avoid wasting the $I$. rubescens resources.
\end{abstract}

\section{Introduction}

It is set in the Chinese Pharmacopoeia (2015 Ed.) that Rabdosiae Rubescentis Herba (traditional Chinese medicine) is the dry aerial portions of Isodon rubescens (Hemsl.) H. Hara (Chinese Pharmacopoeia 2015 Ed.). I. rubescens belongs to Labiatae family (Flora of China 1979). There are much resources of I. rubescens in the Taihang Mountain in China. Rabdosiae Rubescentis Herba are used as traditional Chinese medicine for the treatment of sore throat, inflammation and gastrointestinal problems ((Sun et al. 2006). Oridonin is a bioactive chemical component in I. Rubescens, and has potent in vitro and in vivo activity against human cancer cells (Ikezoe et al. 2003, Leung et al. 2005 and Bai et al. 2010). Growers of medicinal plants usually harvest the aerial portions of $I$. rubescens and then dry it in the sun before sale as Rabdosiae Rubescentis Herba. I. rubescens is subshrub plant with 3 - 4 years of life. The root of I. rubescens is very flourishing. The weight of I. rubescens root is usually larger than that of its aerial parts. The reports about medicinal compositions in the root of I. rubescens are scanty. Therefore, the value of $I$. rubescens root is not clear. In addition, there are differences between the contents of medicinal compositions in I. rubescens stem and those in its leaf. In this study, the difference between the accumulation of oridonin in different portions of I. rubescens was analysed to fully exploit I. rubescens resources and reasonably utilize Rabdosiae Rubescentis Herba.

\section{Materials and Methods}

Shimadzu HPLC-2010 instrument, shimadzu (C18 reverse-phase column, $5 \mu \mathrm{m}, 250 \times 4.6$ $\mathrm{mm}$ ), lectronic analytic balance (precision: 0.0001), ultrasonator and rotary evaporator were used. Methanol (AR), ethanol (AR) and acetonitrile (HPLC grade) were used as reagents. Standard oridonin $(99.8 \%)$ were purchased from Sichuan Weikeqi Biotechnology Co. Ltd. in China in June 2017.

Thirty plants of $I$. rubescens were randomly dug in Guanshan of Xinxiang city in Henan province China in July, 2018. The leaves, stems and roots of these plants were separated and dried to get constant weight at $40^{\circ} \mathrm{C}$.

The dry leaf, stem and root of I. rubescens were respectively crushed and sieved with 80 meshes sieve. Each material was weighed for $2 \mathrm{~g}$ and extracted with $25 \mathrm{ml}$ ethanol solvent (75\%)

*Author for correspondence: <jian19732004@126.com>. 
in the ultrasonic bath for $30 \mathrm{~min}$. The mixture was filtered with filter paper. The residue was extracted with the same solvent $(25 \mathrm{ml}$ of $75 \%$ ethanol) and filtered once again. This filtrate was merged and added to $50 \mathrm{ml}$. The extract was filtered with $0.22 \mu \mathrm{m}$ membrane filter. The extraction of each kind material was repeated three times. Standard oridonin solutions were prepared at 0.001 , $0.005,0.025,0.05$ and $0.15, \mathrm{mg} / \mathrm{ml}$ respectively.

The Diamonsil C18 reverse-phase column $(5 \mu \mathrm{m}, 250 \times 4.6 \mathrm{~mm})$ was used as HPLC column. The temperature in HPLC column was $35^{\circ} \mathrm{C}$. The volume of extract injected was $10 \mu \mathrm{l}$. The gradient mobile phase consists of acetonitrile and water. The content $(\mathrm{v} / \mathrm{v})$ of acetonitrile in the gradient mobile phase varied from 25 to $29 \%$ in $0-10 \mathrm{~min}, 29 \%$ in $10-15 \mathrm{~min}$ and 29 to $30 \%$ in $15-20 \mathrm{~min}$. The flow rate of mobile phase was $0.8 \mathrm{ml} / \mathrm{min}$. A variable wavelength recorder was set at $238 \mathrm{~nm}$ to detect ingredients eluted from the column.

These standard solutions and prepared extracts were respectively analyzed according to the above HPLC method. Chromatography peak areas of oridonin in each chromatogram were respectively recorded. These contents of oridonin in extracts were analyzed according to their chromatography peak areas and the standard curves (relating these peak areas to their contents). All of the data were analyzed with SPSS (Statistical Product and Service Solutions).

\section{Results and Discussion}

The HPLC chromatogram of standard oridonin is presented in Fig. 1. The retention time of oridonin is $14.304 \mathrm{~min}$.

The standard curve of oridonin is set up according to the contents and their corresponding peak areas (Table 1 and Fig. 2). The adopted standard curve of oridonin is $y=10020360.7899 \times+$ 685.1315 (x: Concentration, y: Peak area, $\mathrm{R}^{2}=0.9999$ ).

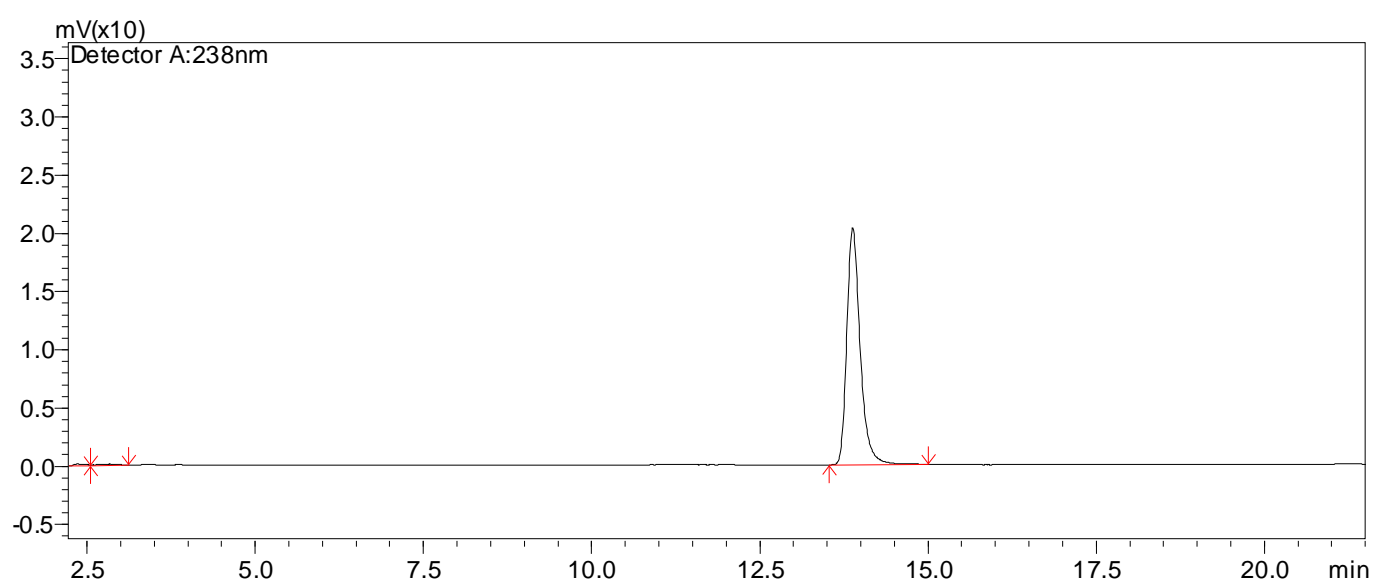

Fig. 1. HPLC chromatograms of standard oridonin.

The peaks of oridonin in extract chromatograms were identified according to their retention time in HPLC (Fig. 3). The concentrations of oridonin in extracts were analyzed according to their peak areas and standard curves (Table 2). The contents of oridonin in I. rubescens materials were analyzed according the methods of preparation extract. 
Table 1. HPLC analysis results of standard oridonin.

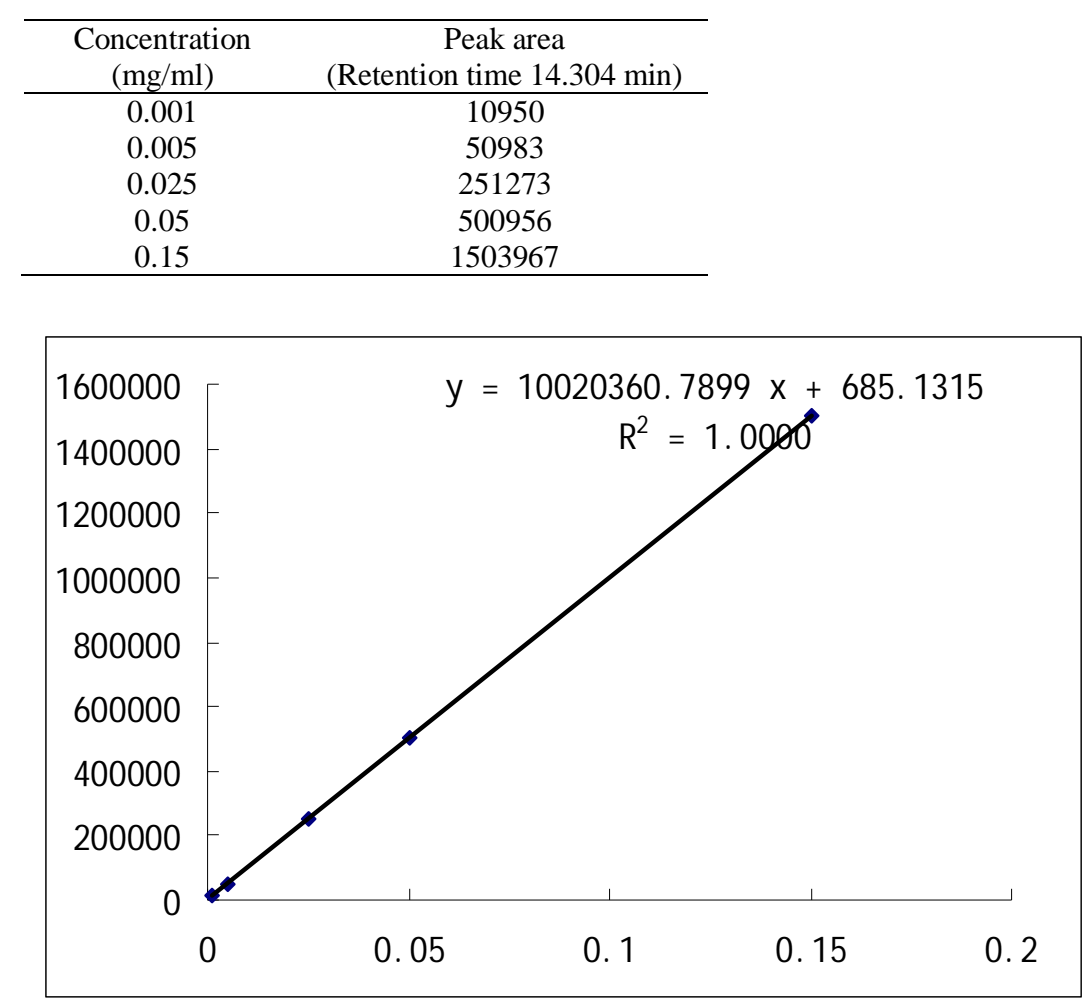

Fig. 2. Standard curves of oridonin.

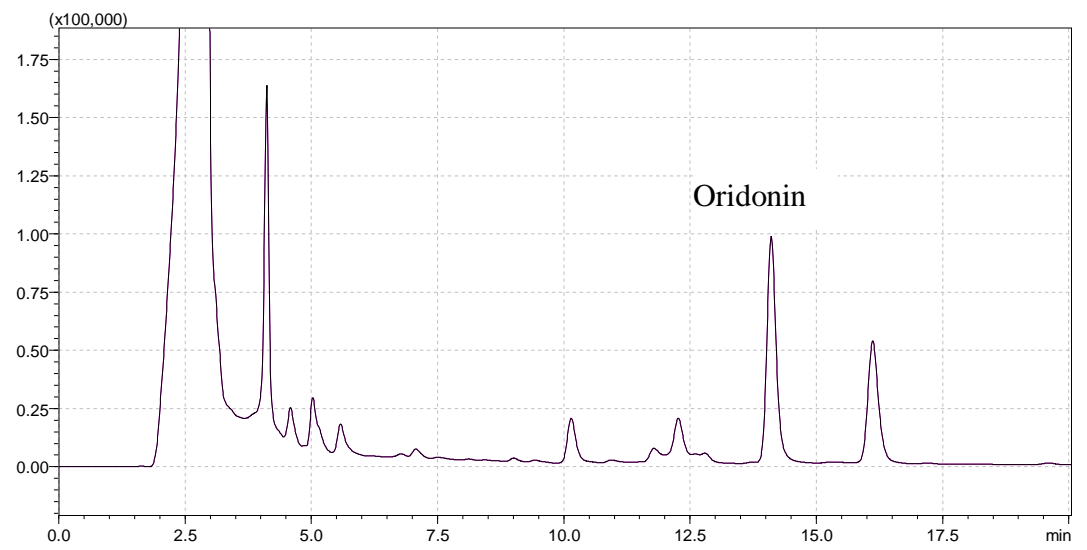

Fig. 3. HPLC chromatograms of I. rubescens materials.

The results showed that there was large difference between the contents of oridonin in the different portions of $I$. rubescens. Then the variance and multiple comparisons on these contents of oridonin in the different portions of I. rubescens were analysed (Table 2). 
The differences between the contents of oridonin in different portions of $I$. rubescens were extremely significant $(\mathrm{p}<0.01)$. The content of oridonin in the leaf of $I$. rubescens is higher than that of other portions. The stem of I. rubescens owns close content of oridonin to that of leaf. The root of I. rubescens has lowest content of oridonin in the three portions. But the content of oridonin in the root achieve $0.0811 \mathrm{mg} / \mathrm{g}$.

Table 2. Contents of oridonin in I. rubescens materials.

\begin{tabular}{llllc}
\hline Part & $\begin{array}{c}\text { Peak } \\
\text { area }\end{array}$ & $\begin{array}{l}\text { Concentration } \\
(\mathrm{mg} / \mathrm{ml})\end{array}$ & $\begin{array}{l}\text { Content } \\
(\mathrm{mg} / \mathrm{g})\end{array}$ & $\begin{array}{c}\text { Multiple } \\
\text { comparisons* }^{*}\end{array}$ \\
\hline Leaf & 1332583 & 0.132918953 & 3.322974 & \\
Leaf & 1115786 & 0.111283315 & 2.782083 & $3.106^{\mathrm{a}}$ \\
Leaf & 1288220 & 0.128491669 & 3.212292 & \\
Stem & 502622 & 0.050091534 & 1.252288 & \\
Stem & 571380 & 0.05695336 & 1.423834 & $1.385^{\mathrm{b}}$ \\
Stem & 593876 & 0.059198388 & 1.47996 & \\
Root & 35001 & 0.003424473 & 0.085612 & \\
Root & 30327 & 0.002958023 & 0.073951 & $0.0811^{\mathrm{c}}$ \\
Root & 34271 & 0.003351622 & 0.083791 & \\
\hline
\end{tabular}

*The mean difference is significant at the 0.01 level. The different letters indicate, there is obvious difference between these means, The same letters indicate there is not obvious difference between these means.

The dry aerial portions of Isodon rubescens is uesd as Rabdosiae Rubescentis Herba which is specified in the Chinese Pharmacopoeia (Chinese Pharmacopoeia 2015 Ed.). There are very a few published reports about the accumulation of oridonin in different portions of Isodon rubescens (SU et al. 2009). The result of present study and other published reports similarly showed that the contents of oridonin in the aerial portions (especially leaf) of Isodon rubescens are all higher than that of root (SU et al. 2009). The content of oridonin in the root achieve $0.0811 \mathrm{mg} / \mathrm{g}$. Therefore, the root of $I$. rubescens has considerable medicinal value. The root would be exsiccated in 3- 4 years if it be harvested for I. rubescens possesses 3 - 4 years of life. The root in long age should be utilized to avoid wasting the $I$. rubescens resources.

\section{Acknowledgement}

This study was supported by Science and Technology Research Project of Henan Province (No. 182102310634 \& No. 152300410093$)$.

\section{References}

Bai NS, He K, Zhou Z, Tsai ML, Zhang L, Quan Z, Shao X, Pan MH and Ho CT 2010. Ent-Kaurane diterpenoids from Rabdosia rubescens and their cytotoxic effects on human cancer cell lines. Planta Med. 76(2): 140-145.

Chinese Pharmacopoeia Committee 2015. Pharmacopoeia of the People's Republic of China, 2015 ed, Part I. Chemical Industry Press, Beijing, 106-107.

Flora of China Committee 1979. Flora of China (volume 66). Science Press, Beijing, 457-458.

Ikezoe T, Chen SS, Tong XJ, Heber D, Taguchi H and Koeffler HP 2003. Oridonin induces growth inhibition and apoptosis of a variety of human cancer cells. Int. J. Oncol. 23(4): 1187-1193.

Leung CH, Grill SP, Lam W, Han QB, Sun HD and YC Cheng 2005. Novel mechanism of inhibition of nuclear factor-kappa B DNA-binding activity by diterpenoids isolated from Isodon rubescens. Mol. Pharm. 68: 286-297. 
Sun HD, Huang SX and Han QB 2006. Diterpenoids from Isodon species and their biological activities. Nat. Prod. Rep. 23: 673-698.

SU Xiuhong, LI Xueju, DONG Chengming and Wang Weili 2009. Study on the dynamics of spatial accumulation of oridonin and rosmarinic acid of rabdosia rubesens (Henmsl.) Hara. China Medical Herald 6(21): 5-6.

(Manuscript received on 16 October, 2018; revised on 18 February, 2019) 